\title{
Ensinando futuros professores a ensinar: reflexões de uma experiência didática
}

Ivan Fortunato ${ }^{1}$

\section{Considerações iniciais}

Este ensaio foi escrito com o objetivo principal de analisar as atividades práticas desenvolvidas ao longo da disciplina de didática, conduzidas no primeiro semestre de 2017, no curso de licenciatura em física do Instituto Federal de Itapetininga, no sudoeste paulista. Nesses meses, todas as aulas catedráticas, teóricas, retóricas e discursivas, foram substituídas por um período de intervenções em uma instituição de educação não-formal, cujo trabalho prioritário é a integração social e o estabelecimento de vínculos de crianças em situações de vulnerabilidade.

Obviamente, tal "troca" não foi acaso, tendo sido motivada por uma investigação entranhada nas bases mais sólidas e dissolutas da educação escolar (HERRAN; FORTUNATO, 2019; 2017; FORTUNATO, 2017a; 2016a; 2016b; 2016c; FORTUNATO; PENTEADO, 2015), das práticas de ensino (CUNHA; TERRA; FORTUNATO, 2017; FORTUNATO, 2016d), e da (minha) própria formação inicial de professores para a educação básica (FORTUNATO, 2018; 2017b).

Na disciplina de didática, portanto, os licenciandos tiveram a oportunidade de planejar, executar e avaliar todo seu próprio percurso formativo que, por meio de "oficinas" de ciências para crianças, puderam aprender a refletir sobre a atividade docente. Foi-Ihes oportuno, ainda, vivenciar as incertezas e instabilidades do cotidiano educacional, sendo que foi preciso novo planejamento durante a execução do projeto, bem como improvisar diante circunstâncias nãofavoráveis e exercitar a criatividade para ensinar (e aprender com) as crianças da instituição. Assim, revistar o percurso dessa disciplina de didática torna-se oportunidade para verificar possíveis avanços e retrocessos das estratégias e práticas voltadas para formação de professores.

Para alcançar o propósito de refletir sobre a experiência na formação de futuros professores, este ensaio foi elaborado em duas seções. Na primeira, nomeada "dos

\footnotetext{
${ }^{1}$ Instituto Federal de São Paulo. Itapetininga/SP. Endereço eletrônico: ivanfrt@yahoo.com.br Periódico Horizontes - USF - Itatiba, SP-Brasil - e019014
} 
antecedentes", busquei compreender como algumas frustrações particulares, da minha própria formação docente inicial, foram úteis no amadurecimento de uma prática pedagógica voltada ao efetivo exercício da profissão. Na sequência, em "ação-reflexão-ação", foram descritos o planejamento e a execução da intervenção didática realizada no primeiro semestre de 2017.

Ao final, espera-se que a descrição e revisão dessas experiências didáticas tenham alguma reverberação na condução de novas e mais aprofundadas formas de se ensinar futuros professores a respeito do cotidiano da profissão.

\section{Dos antecedentes}

Pois bem... mas, não vá falar nisso em parte alguma. Você sabe o que é uma universidade, um diploma universitário? É a indispensável pedra de toque para todo homem que quer ser bem-sucedido no ensino. Meu projeto, ou meu sonho, é obter um grau numa universidade e, depois, tomar ordens. Indo viver em Christminster, ou perto de lá, estarei de certo modo em pleno quartelgeneral da ciência. E, se meu projeto for realmente realizável, creio que terei mais probabilidades de vencer estando lá do que estando em qualquer outra parte (HARDY, 1994, p. 19).

Pode-se dizer que o trabalho de didática revisitado neste artigo teve grande influência das palavras ditas pelo professor Richard Phillotson para o menino Judas Fawley, na ocasião em que se despedia da pequena aldeia para perseguir o sonho de conquistar seu diploma universitário. O emblemático trecho, reproduzido na epígrafe, retrata o momento em que Judas decidiu que iria ao encalço de seu próprio diploma, pois também queria vencer na vida. Lamentavelmente, apesar de penoso empreendimento, Judas apenas conseguiu estar nas proximidades do "quartel-general da ciência", pois nunca lhe foi permitido sequer divisar o que havia em seu interior.

A primeira vez que li esse clássico (Judas, o obscuro) foi no início da graduação em pedagogia, logo na alvorada do século. Naquela época, vivia angustiante paradoxo, pois, nas aulas clássicas que tomava no curso de formação de professores, lia e ouvia a respeito do ensino voltado aos interesses dos educandos, partindo dos saberes já constituídos para a construção de 
novos conhecimentos. Não obstante, o cronograma de leituras era estabelecido arbitrariamente, assim como os objetivos de cada disciplina, seus métodos avaliativos, o rol de atividades e o desempenho mínimo esperado. Dessa maneira, as desventuras de Judas Fawley apenas ampliaram as aflições que experimentava como aspirante da profissão docente, pois seu autor, Thomas Hardy (1994), conseguiu deixar a nu a abissal distância entre a universidade e o mundo para o qual o ensino superior supostamente prepara seus egressos.

Percebi, com a tragédia de Judas, que o termo "quartel-general da ciência" não seria nenhum exagero para qualificar a universidade. Aliás, foi assim que evidenciei que o conhecimento rebuscado, com o qual tomava contato nas aulas curriculares do ensino superior, era mero capricho de um lugar pretensioso e sisudo. Afinal, os quatro anos de estudos sistemáticos deveriam, em princípio, capacitar seus egressos para a sala de aula da educação infantil e dos anos iniciais do ensino fundamental, bem como para a gestão educacional. Dessa forma, tomei lições sobre a estrutura e funcionamento da educação básica, sobre filosofia, história, política e psicologia da educação, sobre metodologias e práticas de ensino de alfabetização, ciências, matemática, história e geografia, sobre didática e avaliação, e sobre gestão, coordenação e orientação escolar.

Não obstante, das mais de três mil horas de formação, distribuídas ao longo de oito semestres letivos, estive dentro de uma escola por apenas alguns dias ao longo de dois semestres, cumprindo a carga-horária do estágio curricular supervisionado, sem que eu, nem as escolas que me acolheram tivessem qualquer ideia do que deveria ou poderia fazer. Assim, não fosse a vontade de uma professora em particular, que desenvolveu uma ação integradora dentro de uma escola estadual de ensino médio, ouso dizer que teria concluído o curso que me capacitava para o ensino de crianças desde seu primeiro ano de vida e para a gestão de uma unidade escolar, sem que tivesse a mínima noção do campo de trabalho para o qual estava plenamente habilitado.

De certo modo, não fui tão obstinado quanto Judas Fawley, pois não permiti que minha

Periódico Horizontes - USF - Itatiba, SP-Brasil - e019014 
decepção com a academia se tornasse notável desgraceira ${ }^{2}$. Dessa forma, iniciei minha vida profissional longe dos muros da academia, predizendo jamais retornar.

No entanto, conforme narrado em outros dois ensaios, retornei à segurança do quartelgeneral alguns anos mais tarde (cf. FORTUNATO, 2018; 2017b). O começo, confesso, foi bastante desconfortável. Fiquei um pouco mais aliviado quando apurei que Füller (1969), no final dos anos 1960, já havia anotado que nesta fase inicial, as preocupações do professor são centradas nele mesmo, sendo este o momento de se questionar sobre sua própria "posição" com relação à escola e seus alunos. Por isso, é comum que um professor em início de carreira reitere perguntas do tipo: como controlar a classe?; como adequar o conteúdo?; como avaliar os alunos?; como os alunos avaliam minha aula?; o que pensam a coordenação e a gestão da instituição a respeito de minha prática docente?

Desse modo, nesse prefácio de carreira docente, meu desempenho era totalmente catedrático, normativo e pretensioso. Nada diferente do que Füller (1969) anotou a respeito de professores em início de carreira que, geralmente, procuram "estimar" o tipo de suporte que podem ter da gestão e da coordenação, além de buscar parcerias de trabalho entre os pares e o pessoal da administração e, ainda, aferir sua aceitação como profissional em todos os locais da instituição (salas de aula, sala de professores, biblioteca etc.).

Pode-se dizer, inclusive, que havia certa aspereza no meu trato com os estudantes, como que se quisesse manter uma distância segura entre o que eu deveria saber e o que poderia ensinar, ou entre o que deveria ensinar e o que poderia utilizar como meio de verificar seu desempenho. Essa separação também já tinha sido identificada por Füller (1969) como algo bastante regular entre professores novatos, pois está relacionada diretamente com preocupações sobre autoridade, conteúdo e avaliação.

Deixei-me influenciar, então, por conselhos dos mais experientes, inclusive a respeito do comportamento de alguns estudantes e da maneira como avaliá-los. Dessa forma, tomei a objetividade e a qualidade acadêmica como critérios decisivos para aferir o desempenho de

\footnotetext{
${ }^{2}$ Tal predicado refere-se às mazelas vividas por Judas, incluindo o suicídio coletivo de seus três filhos (cf. HARDY, 1994).
}

Periódico Horizontes - USF - Itatiba, SP-Brasil - e019014 
meus estudantes e, portanto, deliberar a respeito de quem estaria apto a prosseguir na jornada em busca de seu diploma universitário, e de quem deveria refazer o percurso até alcançar a excelência mínima necessária.

Por um lado, as anotações de Füller (1969) trazem certo conforto ao expressar que essas preocupações tomam conta da maioria dos professores em início de carreira. Mas, por outro lado, é inquietante notar que tais atitudes apenas reforçavam a qualidade de "fortaleza" da universidade, a qual se tornou obsessão e tormento na vida de Judas, esposa e filhos. Na verdade, ao revisitar esse período inicial, fica patente o quanto as preocupações iniciais ofuscavam o trabalho de formar professores, perfazendo da sala de aula (e suas atividades) um mundo à parte. Com isso, portanto, fui reconhecendo, na minha prática, a metafórica fortaleza do conhecimento que tanto atraía Judas, mas que paradoxalmente não o permitia se aproximar.

Essa inquietação foi apenas se tornando mais acentuada conforme fui conhecendo o legado deixado por Freinet $(2004 ; 1998 ; 1975)$, especialmente no que diz respeito ao "bom senso" na educação; sua sensibilidade para ver, ouvir e compreender os meios que cada pessoa tem para aprender e demonstrar interesse pelas coisas da vida e da escola e suas técnicas, lastreadas pelo entendimento de que a aprendizagem se dá de forma natural, e não impositiva.

Esse autor escreveu uma passagem que, para mim, reproduz (quase que fielmente) o que sentia na época em que eu frequentava a escola básica, mas também como aluno do ensino superior e, mais tarde, quando comecei a questionar minha própria prática como professor de licenciatura. Freinet anotou: “[...] ouvia-se a sineta; produzia-se imediatamente como que um vazio no nosso ser. A vida detinha-se ali, a escola começava" (1975, p. 53, grifo meu).

Tal constatação, pensei, não deveria somente repousar nos anais da educação como uma crítica contundente à educação escolar. Isso porque, reproduzir essa frase, mas manter a mesma lógica, o mesmo controle, a mesma velha forma tradicional de educar, a partir de uma posição de fortaleza, equivale conservar e nutrir a educação que se separa da vida. Ao perceber, com Freinet (1975), que minha prática estava próxima daquela que tanto me angustiava na infância, adolescência e anos de formação inicial, ficava evidente que não poderia mais me dar ao luxo de procurar pela minha "posição" como professor iniciante, centrando minhas ações em mim 
mesmo, como se estive à procura de uma aceitação e respeito entre os estudantes, pares e superiores.

Destarte, percebi que era preciso tentar mudar um caminho que já estava prescrito: os anos de experiência me transformariam em um professor mais seguro com relação ao controle da classe, às técnicas de ensino e aos mais avançados meios de avaliação, bem como teria aprendido a lidar com os superiores, teria formado alianças de trabalho com colegas professores e técnicos da administração e seria reconhecido como docente da licenciatura em todos os locais da instituição. Tudo isso, certamente, seria uma ótima contribuição para manutenção do status quo de quartel-general da ciência. Assim, encontrei novamente ancoradouro em Freinet (1977) quando, ao demonstrar sua fórmula de escola, observou que o aprendizado não se dá pelas explicações intelectuais ou pela exposição das leis e fórmulas gerais, mas por um "processo geral universal de tentativa experimental ${ }^{3 \prime \prime}$ (p. 21). Assim sendo, registrou:

O processo é realmente infalível, mas pressupõe uma reviravolta total da técnica educativa; em vez de situarmos no início da aprendizagem o estudo sistemático das leis e das regras, inserimos a tentativa experimental da criança num meio rico, acolhedor e propício, que the oferece flores perfumadas com que fabricar o seu mel. O estudo das regras e das leis só virá mais tarde, quando o indivíduo tiver transformado as suas experiências em indeléveis técnicas de vida (FREINET, 1977, p. 28).

A simplicidade com que foi apresentada essa "reviravolta total" me fez pensar que, talvez, valesse a pena utilizar essa guinada como uma forma de "tentativa experimental" em minhas próprias aulas. Afinal, não poderia ser pior do que a angustiante forma de educação, com a qual convivia desde o primeiro contato com a escola. Nesse entremeio, veio a vontade de organizar um ambiente rico e propício para que os licenciandos pudessem tatear pelo cotidiano vivo das instituições de educação que, potencialmente, os aguardam ao final do curso superior como local de trabalho.

Foi percebido, então, que há um excesso de obstáculos e impasses para que se possa

\footnotetext{
${ }^{3} \mathrm{O}$ termo original tâtonnement expérimental foi traduzido como tateamento, tateio ou tentativa experimental, mas, poder ser entendido apenas como tentativa-e-erro.
}

$$
\text { Periódico Horizontes - USF - Itatiba, SP-Brasil - e019014 }
$$


estabelecer um meio acolhedor para aprender a ser professor. Da burocracia para que os licenciados possam tomar lições fora da sala de aula à permissão (quase ministerial) para que se possa ajudar uma escola a se tornar uma comunidade de ensinamentos e aprendizagens colaborativos. Mas, na insistência e persistência de querer promover a reviravolta proposta por Freinet (1977), realizamos nosso empreendimento inaugural no primeiro semestre de 2017, depois de quase dois anos de investidas para o estabelecimento de cooperação entre local de formação de professores e os locais de ação do professorado já formado.

\section{Ação-reflexão-ação no ensino de didática}

Judas começava a compreender que a vida de uma cidade é um livro de humanidade mais palpitante, mais variado e resumido que a vida da Universidade. (HARDY, 1994, p. 212)

Diminuir a distância entre o apresentado na formação inicial docente e o campo de ação do professor passou a ser objetivo central das minhas preocupações profissionais. Talvez Judas tenha percebido essa necessidade tarde demais, quando a obsessão pelo "quartel-general" já havia Ihe consumido boa parte da vida. Não obstante, ainda que tardiamente, ele notou que viver e observar a vida acontecendo é muito mais fértil e agradável do que ler a seu respeito. Algo muito semelhante pode ser afirmado a respeito da escola e das práticas de ensino.

Assim, com essa preocupação latente, parti em busca de passagens que pudessem aproximar os universitários da comunidade escolar. Claro que alguns caminhos já tinham sido desbravados, tais como os programas de estágio curricular supervisionado e o subprojeto do Programa Institucional de Bolsa de Iniciação à Docência, o PIBID. Outra forma bem fundamentada de aproximação com a comunidade escolar já estava sendo conduzida há algum tempo, por conta de parceria celebrada entre prefeitura e o Instituto Federal, na qual a primeira cederia equipamentos e bolsas para estagiários, e o segundo cederia o espaço e os estudantes para atuarem como guias educacionais de um "parque do conhecimento de ciências". Mesmo assim, apesar de toda diligência com que essas ações tenham sido plenamente executadas, ainda

Periódico Horizontes - USF - Itatiba, SP-Brasil - e019014 
parecia haver certa distância entre a academia e a escola, como se, em alguns casos, a fortaleza do conhecimento estivesse sendo condescendente, permitindo pequena aproximação.

Iniciei, portanto, no final de 2015, algumas tentativas para estabelecer laços com escolas. Organizei reuniões com a responsável pela diretoria regional de ensino, do governo estadual (para ações no segundo ciclo do ensino fundamental e médio) e com a secretária de educação municipal (para ações no primeiro ciclo do ensino fundamental). Algumas reuniões depois, parecia ainda não ter encontrado o caminho adequado para desenvolver projetos de intervenção ou de ensino com as escolas estaduais. Contudo, na esfera municipal, apesar de algumas reuniões frustradas, tive a oportunidade de conhecer uma diretora disposta a partilhar suas dificuldades e receber apoio.

Assim, na primeira metade de 2016, visitei a escola algumas vezes com o intuito de ouvir suas dificuldades e identificar qual poderia ser minha contribuição. Na segunda metade do ano, com ajuda dos estudantes de licenciatura em física matriculados na disciplina de Prática Docente, colocamos em ação uma proposta de jogo de RPG desenvolvido para o ensino de ciências (OLIVEIRA; FORTUNATO, 2017), bem como pudemos fazer parte da sétima edição da feira de ciências da escola com uma maquete de vulcão. Neste mesmo período, uma aluna do curso de especialização desbravava o uso do laboratório de informática para o terceiro ano, demonstrando aos professores e às crianças daquela escola, como um simulador poderia estimular e favorecer o aprendizado da matemática (FALCHI; FORTUNATO, 2018).

Essas atividades pontuais foram fundamentais para tomar fôlego e continuar insistindo na relação escola-universidade. Dessa forma, tomei como meta para o semestre seguinte articular uma disciplina focada exclusivamente na ação integrada, problematizando a didática a partir de situações autênticas, vivenciadas no futuro campo de trabalho dos licenciandos. Para tanto, era preciso apresentar, conforme havia alertado Freinet (1977), um ambiente propício à aprendizagem dos estudantes. Nesse caso, era preciso encontrar um local em que os licenciandos pudessem planejar-ensinar-refletir algo que estivessem confortáveis o suficiente para que o propósito principal de todo esse exercício fosse alcançado: perceber as contingências do trabalho docente e toda complexidade que se esconde na relação ensino-

Periódico Horizontes - USF - Itatiba, SP-Brasil - e019014 
aprendizagem.

Para definir qual o local de ação seria o mais próximo de um ambiente fértil para que os licenciandos pudessem esboçar o início de sua prática docente, tomou-se como critérios de seleção as três categorias indicadas por Martins (2009): (1.) infraestrutura e aspectos físicos, (2.) ambiente coletivo de trabalho, e (3.) prática profissional dos estudantes.

Basicamente, o local ideal seria aquele cuja infraestrutura de trabalho não fosse precário, mas que pudesse oferecer suporte suficiente para a prática, como mesas e cadeiras para seus alunos e para os licenciandos, material de escritório como lápis, papel, tesoura etc., livros para consulta, espaço para atividades dinâmicas etc. Com relação ao segundo item, o local ótimo de ação seria aquele em que as pessoas da instituição fossem motivadas para o trabalho, além de dispostas a colaborar com as atividades e o aprendizado dos licenciandos. Por último, a instituição deveria permitir que os licenciandos tivessem liberdade de atuação, desde que, obviamente, supervisionados por mim.

Durante a seleção da instituição, foi preciso adicionar mais um condicionante: sua localização. Isso porque, quanto mais próximo o local de ação fosse do Instituto Federal, maiores as chances de conseguir mobilizar todos os estudantes para a prática.

Dessa forma, os condicionantes para o estabelecimento de um ambiente próprio para ensinar a ensinar, somados com as dificuldades já mencionadas de iniciar parcerias com as escolas municipais e estaduais, direcionaram a escolha do local para uma instituição de educação não-formal. Igualmente regida pela lei de diretrizes e bases nacional, a educação não-formal se constitui como um campo de trabalho possível para egressos de um curso de licenciatura. Assim, próximo ao Instituto Federal está localizada uma das mais antigas organizações nãogovernamentais (ONG) da cidade, constituída para o fortalecimento de vínculos socioeducativos de crianças em situação de risco. Após algumas visitas e reuniões com o corpo diretivo, verificouse que a ONG atendia a todos os qualificadores de um ambiente próprio para se aprender a ensinar.

Definiu-se, então, após reunião de planejamento com a direção da instituição que os estudantes de licenciatura teriam encontros quinzenais com as crianças mais velhas atendidas Periódico Horizontes - USF - Itatiba, SP-Brasil - e019014 
pela ONG, isto é, entre nove e 11 anos de idade, com o objetivo de ensiná-las estruturas elementares de ciências. Todo conteúdo, material e forma de atuação ficariam sob minha responsabilidade. Programamos o início dos trabalhos para meados de março, dando tempo suficiente para que o plano de ação fosse elaborado em fevereiro, junto com os estudantes da licenciatura, preferencialmente pelos próprios estudantes. As idas quinzenais à ONG foram propostas por mim, pois, dessa forma, as intervenções didáticas teriam tempo de revisão, reflexão e replanejamento - se necessário.

Esse plano foi inspirado pelo processo dialogado, no qual o trabalho educativo é combinado entre as partes envolvidas (professor, alunado etc.), conforme exposto por González (2002) a respeito do Movimento da Escola Moderna em Portugal. Esse autor apontou que a reflexão constante sobre a prática pedagógica constitui um metafórico "espelho" para analisar a própria docência sendo "que quanto mais aprofundada é a capacidade de reflexão de um profissional da educação, melhor é o aproveitamento pedagógico que pode fazer dos instrumentos e técnicas que utiliza" (p. 217). Assim, pensar em grupo e ter pausas para (re)pensar a ação parecia atender boa parte dos requisitos de um ambiente propício para aprender a ser professor.

No primeiro dia de aula da disciplina, uma breve introdução sobre didática foi feita. Tomamos, en passant, a didática geral de Pilleti (2004), a didática como teoria da instrução e dos processos de ensino de Libâneo (1994) e as competências para ensinar de Perrenoud (2000). Mas, logo partimos para o que Ventura (2002) chamou de "pedagogia de projetos": um movimento que se inicia com a problematização, passa pela partilha das informações necessárias sobre o público e o ambiente do local de ação, e segue com o engajamento dos envolvidos. Para o autor, essa pedagogia requer do professor universitário o estabelecimento da situaçãoproblema, a elaboração de um "contrato pedagógico" com os licenciandos, a condução de reuniões pedagógicas regulares, o zelo pelos licenciandos e pela instituição da intervenção e, ao final, a colaboração com a reflexão final de toda atividade.

Assim, depois de apresentar a teoria mais basilar da didática e da concepção da pedagogia por projetos, apresentei a situação-problema aos licenciandos, contando a respeito da ONG, do

Periódico Horizontes - USF - Itatiba, SP-Brasil - e019014 
público atendido, horário de trabalho etc. e da oportunidade que teríamos para investigar a didática na prática.

Nesse sentido, permiti que os catorze estudantes matriculados na disciplina discutissem quais conteúdos seriam ensinados, de que maneira, com qual material e por quem. Pedi que se organizassem da forma que lhes parecesse a mais adequada, inclusive deliberando a respeito das funções a serem desempenhadas por cada um, pois seria preciso pessoas para ensinar, outras para dar apoio e, ainda, algumas para observar e registrar, sendo que estes registros seriam fundamentais para que a reflexão pudesse ser levada a cabo com propriedade.

É preciso deixar expresso que não foi fácil planejar: muitas ideias, muitas possibilidades, muitos devaneios, houve bastante discussão a respeito do que poderia ser apresentado, mas, nada foi concretizado nas primeiras aulas destinadas ao planejamento. Por isso, foi preciso intervir. Desenhei um quadro na lousa indicando as datas quinzenais (que totalizariam oito encontros) e as duas horas e meia de tempo de ação por encontro. Escrevi as perguntas "O QUE?", "QUEM?", "COMO?", “COM QUE?" e pedi que tivessem como foco durante o planejamento o preenchimento daquele quadro. Foi percebido, então, que o planejamento precisaria ser feito de acordo com o que tivessem acesso de fato, ou seja, o que conheciam bem o bastante para ensinar, com materiais que pudessem acessar no Instituto Federal ou que fosse de baixo custo, mas, principalmente, que alguém teria que tomar a frente para conduzir as ações de ensino.

Com bom-senso e consenso, os licenciandos planejaram duas atividades principais. Uma delas seria a condução de pequenas oficinas de ciências, nas quais as crianças construiriam os experimentos e/ou se envolveriam em atividades dinâmicas sobre física como forma de vivenciar conceitos que tomariam contato somente anos mais tarde, no ensino médio. Essas oficinas se desdobraram, portanto, em várias atividades de óptica como a construção de um "disco de Newton" e de uma "câmara escura", de mecânica, como a "lata adestrada" e a "caneca assustada ${ }^{4 \prime}$, e de ondulatória, com o uso de molas e instrumentos musicais de cordas (guitarra, violão, contrabaixo e violino) para demonstrar o som como uma onda mecânica, tratar de

\footnotetext{
${ }^{4}$ O Manual do Mundo explica como fazer um disco de Newton, uma câmara escura, uma lata adestrada e uma caneca assustada: http://www.manualdomundo.com.br, acesso set. 2017.
}

Periódico Horizontes - USF - Itatiba, SP-Brasil - e019014 
intensidade, altura e timbre, além de cantar algumas músicas que alegram a criançada.

A segunda atividade seria a condução de um jogo de Role Playing-Game (RPG) desenhado exclusivamente para o ensino de ciências e matemática e o desenvolvimento de múltiplas inteligências. No jogo, cada criança elabora um personagem que irá representá-la ao longo das aventuras e, por meio do raciocínio lógico, afetivo, interpessoal etc. é que os desafios apresentados aos personagens são superados, ou não. Como o RPG já estava sendo estruturado desde o ano anterior, por meio de um projeto de iniciação cientifica em andamento que já havia sido colocado em experiência na referida escola municipal (OLIVEIRA; FORTUNATO, 2017), era preciso mais tempo para sua execução na ONG.

Por conseguinte, de posse de todo conteúdo a ser ensinado, os licenciandos se dividiram em equipes e organizaram suas funções. Alguns tomaram o papel de liderar, pois conheciam as atividades das oficinas e do RPG melhor que os demais, se responsabilizando pelo conteúdo e forma de aplicação. Os líderes, ainda, tiveram como desafio preparar os demais para que pudessem também conduzir as atividades junto às crianças. Definiram, em conjunto, qual seria a ordem das atividades e quem iria se responsabilizar por registrar cada uma das distintas atividades.

Importante mencionar que os próprios licenciados, ao reconhecerem que o jogo de RPG estava bem estruturado e poderia despertar interesse das crianças da ONG, sugeriram que as crianças fossem separadas em duas turmas para que o RPG pudesse ser conduzido ao longo dos oito encontros. Assim, na primeira metade do tempo disponível para nossa ação a turma $A$ jogaria RPG enquanto a turma B participaria das oficinas de ciências. Na segunda metade do tempo, as turmas se inverteriam. O planejamento estava pronto e os licenciandos preparados para experimentar ensinar.

As atividades começaram no dia combinado. O grupo todo de licenciandos chegou no horário acertado e fomos muito bem recebidos pela equipe da ONG e pelas crianças, que já sabiam da nossa intervenção, embora o conteúdo de nosso trabalho ainda fosse uma surpresa.

De imediato, a equipe de licenciandos foi tomando contato com aspectos que se tornarão comum na atividade docente: a inquietação dos alunos, as conversas, os barulhos, as brincadeiras para chamar atenção do professor e dos colegas, a dificuldade de se conseguir um

Periódico Horizontes - USF - Itatiba, SP-Brasil - e019014 
momento de silêncio para explicar conteúdos e atividades etc. Foi custoso alcançar a calma no ambiente, sendo somente conquistada depois que iniciei uma roda de apresentações, pedindo para que cada licenciando se apresentasse para as crianças e que cada criança se apresentasse para os licenciandos, dizendo nome, idade, ano escolar e o que mais achasse interessante revelar naquele momento introdutório.

Na sequência, os estudantes de licenciatura trabalharam na divisão das turmas $A$ e $B$, e logo se puseram a tentar explicar, de um lado, alguns fenômenos da física e, do outro, a operação de um jogo de RPG que se começa pela criação de um personagem e seus atributos. Na semana posterior, nos reunimos no Instituto Federal para refletir sobre o primeiro encontro e repensar o segundo, com base no que foi observado, aprendido, executado ou não executado. Na próxima semana, portanto, voltamos à ONG renovados.

O percurso formativo para didática seguiu esse ritmo: ação na ONG, revisão e reflexão no Instituto, para nova ação. Durante esse processo, houve a oportunidade de vivenciar algo bastante corriqueiro na educação: os acasos que impedem o progresso das ações dentro do planejado. Um desses acasos foi o não funcionamento de um aparelho eletrônico criado pelos próprios estudantes em outra disciplina do curso de física, que seria utilizado para a demonstração de um experimento. Após algumas tentativas frustradas de fazer o equipamento ligar, a inquietação das crianças e a ansiedade dos licenciados estavam evidentes. Sugeri, então, que a gente retomasse o conteúdo da semana anterior e aprofundasse um pouco mais nas explicações.

Essa situação foi uma ótima oportunidade de vivenciar os imprevistos do cotidiano de um professor e da necessidade de tomar decisões rápidas e assertivas quando se está à frente de uma classe escolar.

Outro acaso ocorrido foi por conta de calendário. Especificamente, uma data programada para ida à ONG foi tomada pelo município como ponto facultativo. Esse ponto facultativo levou a direção da ONG a solicitar mais uma semana de interrupção na ação, pois outra atividade precisaria ser reposta durante o horário reservado para nossa aula de didática da semana seguinte. Isso fez com que a cadência ação-reflexão-ação fosse interrompida para ser retomada apenas três semanas mais tarde, o que implicou novo planejamento, afinal, a sequência didática

Periódico Horizontes - USF - Itatiba, SP-Brasil - e019014 
iniciada já não faria mais sentido, dado o longo período de ausência na ONG. Quando voltamos, o planejamento refeito foi colocado em prática e, neste, incluímos uma visita reversa, ou seja, as crianças foram convidadas para participar de uma visita guiada por nós no Instituto Federal como forma de conclusão do projeto.

Para encerrar a proposta da disciplina, passados os oito encontros com as crianças da ONG, tendo sido apresentadas diversas oficinas de ciências e levado o jogo de RPG ao seu desfecho, e as crianças recepcionadas no nosso Instituto para conhecerem os laboratórios, salas de aula, biblioteca e parque do conhecimento. Posteriormente, nos reunimos novamente no Instituto Federal para nossa reflexão final.

Ventura (2002) sugeriu que para uma atividade conduzida pela ótica da pedagogia por projetos, sua conclusão poderia ser a produção de um objeto concreto, o qual "coloca em movimento as representações dos alunos, confrontando-os com a realidade" (p. 40). No nosso caso, os licenciandos tomaram as lições aprendidas como oportunidade para produzir textos que pudessem descrever e explicar cada passo da atividade, apresentando seus resumos em um congresso local (CORRÊA; KURNICH; FORTUNATO, 2017; GALVÃO; SILVA; FORTUNATO, 2017; RODRIGUES; OLIVEIRA; FORTUNATO, 2017).

Tais produtos se tornaram elementos fundamentais para que fosse possível evidenciar as lições mais significativas que pudemos apreender desse projeto de campo de investigação do campo de ação docente. Do que foi possível constatar pelos relatos orais e/ou expressos de todos os envolvidos, este entrelaçamento teórico-prático foi uma proposta bastante exitosa, pois, de um lado, as crianças da ONG tiveram contato bastante divertido com rudimentos da ciência e, de outro, os licenciandos puderam exercitar elementos da didática em um possível lugar de atuação futuro.

\section{Considerações finais}

Una formación basada más en actitudes que en procesos o en momentos metodológicos normativos sería más beneficiosa para la reflexión, el cambio y la innovación en el docente universitario. Uno de los obstáculos del cambio

Periódico Horizontes - USF - Itatiba, SP-Brasil - e019014 
metodológico es cómo romper inercias e ideologías institucionales obsoletas; romper con imaginarios sociales y personales muy asentados en las estructuras docentes universitarias ${ }^{5}$ (IMBERNÓN, 2016, p. 45).

É preciso concordar com as palavras de Imbernón (2016) reproduzidas na epígrafe: a formação docente requer mais atitude que processos e normas, ao mesmo tempo em que precisa romper diversas barreiras. Estas, por sua vez, são óbices que foram criados pela própria natureza das instituições de ensino, tornando-se, conforme o autor, inerciais: controles rígidos de currículos oficiais enviesados e de frequência do alunado, definições estanques do que seria uma "aula" e de avaliações somativas que, ao término de um período, atestam aprovação ou reprovação dos seus estudantes. Mas, como bem alerta o autor, não são apenas os obstáculos institucionais que dificultam a formação baseada em atitudes.

Assim, para se fazer diferente, com foco na ação, é necessário superar antigos preceitos sobre educação escolar já arraigados no imaginário social. Isso quer dizer que já se tem estabelecido pela tradição, de que uma aula é um momento de aproximadamente 50 minutos de duração (podendo ser duplicado, triplicado etc.) que acontece em um local específico chamado sala de aula, configurada com um quadro (negro, verde, lousa digital, tela de projeção etc.) e diversas carteiras escolares dispostas em colunas, espinha-de-peixe, círculo, semicírculo etc., mas sempre voltadas para o quadro. Nesta sala, durante o momento determinado, existe um/a professor/a que ensina (fala) e distribui tarefas e estudantes que aprendem (ouvem) e executam tarefas individual, coletivas ou em casa. Qualquer coisa que seja diferente desse padrão, portanto, dir-se-á que não se está tendo aula.

Ao longo deste artigo, buscou-se evidenciar como é dispendioso atender ao exposto por Imbernón (2016) e romper com a educação escolar obsoleta e inercial. Partindo dos dissabores vividos na formação inicial docente, aliados às metáforas a respeito da universidade fortaleza de Hardy (1994), e com as preocupações iniciais de um professor em início de carreira apresentados por Füller (1969)

\footnotetext{
${ }^{5}$ Tradução livre: Uma formação baseada mais em atitudes do que em processos ou momentos metodológicos normativos seria mais benéfico para reflexão, mudança e inovação no professor da universidade. Um dos obstáculos para a mudança metodológica é romper inércias e ideologias institucionais obsoletas; romper com imaginários sociais e pessoais muito instalados nas estruturas do ensino universitário.
}

Periódico Horizontes - USF - Itatiba, SP-Brasil - e019014 
foi-se apenas consolidando os obstáculos de se fazer diferente na formação de professores. Mas, as inspirações de Freinet $(2004,1998,1977,1975)$, os resultados promissores de algumas intervenções na escola e a metodologia da pedagogia de projetos de Ventura (2002) ajudaram a balizar uma forma de superar/romper com os obstáculos na busca por uma formação docente.

Füller (1969) anotou que existe uma fase de preocupações tardias na evolução da docência. Essas preocupações teriam como foco não a (metafórica) sobrevivência do professor, mas, a vontade de que seus alunos aprendam as coisas ensinadas. Contudo, penso que esta não pode ser a última etapa evolutiva, pois, existe uma constelação de fatores que interferem no aprendizado: o currículo, as formas de avaliação e controles de frequência, a conjuntura social, política e econômica, as concepções dos papéis de professor e estudante, do conceito de aula, e tantas outras contingências. Portanto, restringir a preocupação docente apenas a empenhar-se que seus alunos aprendam o que se quer ensinar, é deixar de lado diversas possibilidades de formação, inclusive a de que seja permitido que cada estudante desenvolva seu próprio pensamento crítico e descubra coisas além do currículo oficial, tomado como script único para relação professor-aluno.

Em suma, (diversifiquei as conjunções para não ficarem repetitivas), a disciplina de didática descrita e analisada neste artigo, desenvolvida exclusivamente por meio de um projeto de intervenção conduzido praticamente pelos licenciandos foi uma tentativa eloquente de desenvolver uma formação de professores baseada mais em atitudes que em processos, ao mesmo tempo em que foi possível ampliar a perspectiva de que a educação formal somente se dá dentro de uma sala de aula com as atividades, conduzidas pelo docente, voltadas exclusivamente ao conteúdo curricular.

No material que os licenciandos produziram para apresentar no congresso, elementos muito interessantes ficaram registrados: ficou claro que a intervenção não foi "mágica" e que os poucos encontros não foram suficientes para avaliar se ou o que as crianças aprenderam, mas foi notório que as ações didáticas foram importantes para despertar a curiosidade a respeito da ciência. Outros registros apontavam a afetividade na relação com as crianças como algo que pode fortalecer o interesse pelo que os licenciandos pretendiam ensinar. Alguns, inclusive,

Periódico Horizontes - USF - Itatiba, SP-Brasil - e019014 
ficaram surpresos com a perspicácia de algumas crianças em logo apreender o sentido da ciência nos experimentos e até na compreensão do mundo cotidiano.

A relevância da disciplina essencialmente prática também foi assinalada nos produtos escritos, pois os licenciandos perceberam a importância do planejamento ser realizado coletivamente e em confronto com o tempo disponível, os materiais que se tem acesso e, principalmente, em contato com seu público. Outro aspecto que os licenciandos materializaram nas reflexões escritas foi a importância do projeto para o futuro exercício da profissão, especialmente na necessidade de reconfiguração constante dos planos de ensino, pois estes estão sujeitos, como puderam vivenciar, a mudanças repentinas.

Assim, ao final desse semestre letivo, os futuros professores puderem evidenciar nuances do cotidiano da profissão, compreendendo sua complexidade e imprevisibilidade, principalmente porque puderam experimentar essa complexa relação quadripartida: instituiçãoprofessor-conteúdo-aluno. Espera-se que o seu envolvimento nessa disciplina de didática tenha esclarecido, ao menos para estes licenciados, aspectos basilares da profissão docente. Mas, principalmente, fica a esperança de que a produção deste relato de experiência sirva como inspiração para novos e mais consubstanciados projetos de ensino de formação de professores.

\section{Referências}

CORRÊA, M. T.; KURNICH, G. P.; FORTUNATO, I. Role-playing Game (RPG) baseado em ciências e inteligências múltiplas. In: V Congresso de Iniciação Científica do IFSP Itapetininga. Itapetininga: Anais [...], 2017, p.126

CUNHA, C. R.; TERRA, C. N.; FORTUNATO, I. Ateliê de Física para o ensino de termodinâmica: relato de projeto de intervenção escolar. Revista Brasileira de Iniciação Científica, Itapetininga/SP, v. 4, n. 3, p. 28-39, 2017.

FALCHI, L.; FORTUNATO, I. Simulador PhET e o ensino da tabuada na educação básica: relato de experiência. Revista on line de Política e Gestão Educacional, Araraquara, v. 22, n. 1, p. 439-452, 2018.

FORTUNATO, I. Caminhos da formação na licenciatura: de estudante a docente. Revista Práxis Educacional, Vitória da Conquista/BA, v. 14, n. 27, p. 172-185, 2018.

Periódico Horizontes - USF - Itatiba, SP-Brasil - e019014 
FORTUNATO, I. Summerhill, or A. S. Neill's legacy for the liberating well-made head education. Revista Hipótese, Itapetininga/SP, v. 3, n. 2, p. 6-15, 2017a.

FORTUNATO, I. Tornar-se professor: reflexões iniciais sobre um percurso paradoxal. South American Journal of Basic Education, Technical and Technological, Rio Branco/AC, v. 4, n. 1, p. 4-9, 2017b.

FORTUNATO, I. Ainda é preciso ter cuidado: escola?!. InterScience Place, Campo dos Goytacazes/RJ, v. 11, n. 2, p. 86-95, 2016a.

FORTUNATO, I. Aprendendo com Célestin Freinet: o passado ainda é presente. Tendencia Pedagógicas, Madrid (ESP), v. 27, n. 1, p. 251-258, 2016b.

FORTUNATO, I. 50 Anos sem Célestin Freinet, 500 Anos de Retrocesso das Práticas Escolares. Journal for Educators, Teachers and Trainers, Granada (ESP), v. 7, n. 1, p. 174-181, 2016c.

FORTUNATO, I. Ensinando futuros professores sobre literatura infantil: relato de experiência. ETD - Educação Temática Digital, Campinas/SP, v. 18, n. 3, p. 710-718, jul./set. 2016d.

FORTUNATO, I; PENTEADO, C. L. de C. Educomunicação, ou contra a concorrência desleal entre educação e a mídia do espetáculo. ETD - Educação Temática Digital, Campinas/SP, v. 17, n. 2, p. 377-393, maio/ago. 2015.

FREINET, C. Pedagogia do bom senso. Trad. J. Baptista. 7 ed. São Paulo: Martins Fontes, 2004.

FREINET, C. Ensaio de psicologia sensível. Trad. Cristiane Nascimento e Maria Ermantina Galvão Gomes Pereira. 1 ed. São Paulo: Martins Fontes, 1998.

FREINET, C. O método natural II: a aprendizagem do desenho. 1 ed. Lisboa, Portugal: Editorial Estampa, 1977.

FREINET, C. As técnicas de Freinet da Escola Moderna. 4. ed. Lisboa, Portugal: Editorial Estampa, 1975.

FÜLLER, F. F. Concerns of teachers: a development conceptualization. American Educational Research Journal, Washington (DC), v. 6, n. 2, p. 207-226, 1969.

GALVÃO, B. H. L.; SILVA, D. T. da; FORTUNATO, I. Dialogando a ciência com as crianças. In: V Congresso de Iniciação Científica do IFSP Itapetininga. Itapetininga: Anais [...], 2017, p. 51.

GONZÁLEZ, P. F. O movimento da Escola Moderna: um percurso cooperativo na construção da profissão docente e no desenvolvimento da pedagogia escolar. 1 ed. Porto: Porto Editora, 2002.

Periódico Horizontes - USF - Itatiba, SP-Brasil - e019014 
HARDY, T. Judas, o obscuro. Trad. Octávio de Faria. 1 ed. São Paulo: Geração Editorial, 1994.

HERRAN, A. de la.; FORTUNATO, I. Por qué desde la didáctica no se favorece la formación del profesorado?. Pro-Posições (Unicamp), 2019. [no prelo]

HERRAN, A. de la.; FORTUNATO, I. La clave de la educación no está en las nuevas Tecnologías de la Información y la Comunicación (TIC). Acta Scientiarum Education (online), Maringá, v. 39, n. 3, p. 311-317, 2017.

IMBERNÓN, F. Mejorar la enseñanza y el aprendizaje en la universidad. 1 ed. São Paulo: Edições Hipótese, 2016.

LIBÂNEO, J. C. Didática. 34 ed. São Paulo: Cortez, 1994.

MARTINS, A. F. Estágio supervisionado em física: o pulso ainda pulsa... Revista Brasileira de Ensino de Física, São Paulo, v. 31, n. 3, art. 3402, 2009.

OLIVEIRA, L. C. de; FORTUNATO, I. O Role Playing Game baseado nas inteligências múltiplas. Relatório de Iniciação Científica. Itapetininga: Instituto Federal de São Paulo, 2017.

PERRENOUD, P. Dez novas competências para ensinar. 1 ed. Porto Alegre: Artes Médicas, 2000.

PILETTI, N. Didática geral. 23. ed. São Paulo: Editora Ática, 2004.

RODRIGUES, T. A.; OLIVEIRA, V. A. de; FORTUNATO, I. Levando a física para crianças. In: V Congresso de Iniciação Científica do IFSP Itapetininga. Itapetininga: Anais [...], 2017, p.82.

VENTURA, P. C. S. Por uma pedagogia de projetos: uma síntese introdutória. Educ. Tecnol., Belo Horizonte, v. 7, n. 1, p. 36-41, 2002.

Recebido em março de 2018.

Aprovado em março de 2018.

Periódico Horizontes - USF - Itatiba, SP-Brasil - e019014 